\title{
Evaluasi Pelaksanaan Pendistribusian Cold Chain Product (CCP) oleh Salah Satu Pedagang Besar Farmasi (PBF) di Kota Bandung
}

\author{
Dina Sembiring ${ }^{1}$, Nasrul Wathoni \\ ${ }^{1}$ Program Studi Profesi Apoteker, Fakultas Farmasi, Universitas Padjadjaran \\ 2Departemen Farmasetika dan Teknologi Farmasi Fakultas Farmasi, Universitas Padjadjaran \\ JI. Raya Bandung-Sumedang KM. 21 Jatinangor, 45363 \\ *Email: dina16004@mail.unpad.ac.id
}

(Submit 27/7/2021, Revisi 10/8/2021, Diterima 19/8/2021, Terbit 23/8/2021)

\begin{abstract}
Abstrak
Cara Distribusi Obat yang Baik (CDOB), dan juga Cara Distribusi Alat Kesehatan yang Baik (CDAKB) merupakan sebuah syarat mutlak yang harus dipenuhi dan diperhatikan secara seksama oleh distributor farmasi. Pedagang Besar Farmasi (PBF) harus memastikan bahwa kualitas dan kemanjuran produk pada saat pendistribusian sesuai dengan peraturan perundang-undangan yang berlaku. PBF harus memiliki sertifikat CDOB Cold Chain Product (CCP) guna menjamin kualitas obat yang baik, agar produk yang diberikan tetap terjaga khasiatnya. Evaluasi pelaksanaan pendistribusian CCP oleh salah satu PBF di Kota Bandung dimulai dari proses penerimaan, penyimpanan, hingga penyaluran disesuaikan dengan daftar isian (checklist) CDOB. Hasil dari observasi artikel ini yaitu Implementasi pada PBF ini sudah sesuai dengan CDOB guna menjaga mutu dari obat yang didistribusikan.
\end{abstract}

Kata kunci: $C D O B, C C P, P B F$

\section{Pendahuluan}

Pedagang Besar Farmasi (PBF) memiliki peran yang sangat penting dalam menangani, menyimpan, dan mendistribusikan suatu obat yang peka terhadap lingkungan. Terutama pada pendistribusian produk rantai dingin atau cold chain product (CCP). Produk seperti produk farmasi, makanan dingin, makanan beku, dan produk berumur pendek sensitif terhadap suhu, kelembaban, dan intensitas pencahayaan membutuhkan rantai pasokan dingin untuk mengelola perubahan lingkungan (1). Perubahan dan fluktuasi lingkungan mengurangi kualitas produk dan dengan demikian memiliki efek negatif pada konsumen (2). 
Salah satu contoh dari produk CCP adalah vaksin. Vaksin dapat rusak dan tidak berkhasiat ketika tidak disimpan dan didistribusikan pada suhu yang sesuai (10). Suhu pendistribusian dan penyimpanan vaksin harus dipertahankan antara $2-8^{\circ} \mathrm{C}(11)$. Untuk menjaga kualitasnya, vaksin harus terus disimpan dalam kisaran suhu yang ditentukan dari produksi hingga penggunaan. Kurangnya suhu penyimpanan dan transportasi yang tepat untuk vaksin adalah salah satu faktor umum yang membatasi imunisasi lengkap dan merata di banyak negara (12). Kebanyakan individu tidak memiliki sarana, pengetahuan, atau kemampuan untuk membedakan antara vaksin yang efektif dan tidak efektif, yang hanya dapat dilakukan dengan menggunakan peralatan khusus dan teknisi profesional. Selain itu, banyak negara berkembang tidak memiliki kapasitas rantai dingin yang memadai (13).

Fokus PBF adalah memastikan bahwa kualitas dan kemanjuran produk pada saat pendistribusian sesuai dengan peraturan perundang-undangan yang berlaku. Karena pemilihan pemasok logistik atau PBF rantai dingin obat biasanya melibatkan evaluasi beberapa alternatif (14) maka, sesuai dengan peraturan BPOM nomor 6 tahun 2020 tentang perubahan peraturan BPOM nomor 9 tahun 2019 tentang Pedoman Teknis Cara Distribusi Obat yang Baik (CDOB), PBF harus memiliki sertifikat Cara Distribusi Obat yang Baik (CDOB) CCP guna menjamin kualitas obat yang baik, agar produk yang diberikan tetap terjaga khasiatnya. Pada artikel ini akan membahas evaluasi pelaksanaan pendistribusian CCP oleh salah satu PBF di Kota Bandung untuk memastikan pendistribusian CCP dilaksanakan sesuai dengan CDOB.

Logistik rantai dingin dalam industri farmasi sebagian besar berkaitan dengan penyimpanan dan transportasi; pemeliharaan suhu baik di udara maupun di darat. Banyak produk lain mungkin memerlukan perawatan tambahan untuk mempertahankan karakteristiknya, seperti suhu yang berbeda, disimpan atau dipindahkan secara terpisah, dan aliran balik jika ada. Kondisi unik ini mengarah pada proses logistik yang sistematis dengan teknologi tinggi dan pengetahuan di lapangan, termasuk peraturan dan dokumentasi yang relevan (15).

Rantai dingin adalah jenis rantai pasokan dengan suhu yang terkontrol dari tahap produksi, hingga tahap transportasi, penyimpanan, proses distribusi, dan pengiriman ke pengguna akhir $(3,4)$. Rantai dingin adalah istilah yang digunakan untuk menggambarkan kondisi suhu dingin di mana produk tertentu perlu disimpan selama penyimpanan dan distribusi. Mempertahankan integritas rantai dingin memastikan bahwa produk diangkut dan disimpan sesuai dengan kisaran suhu yang disarankan pabrik dari $2^{\circ} \mathrm{C}$ hingga $8^{\circ} \mathrm{C}$ hingga titik pemberian (5). Secara singkat, rantai dingin adalah rantai pasokan barang sensitif yang dikontrol oleh suhu (6). Berdasarkan jenis produknya, pengangkutannya dilakukan dengan truk, kapal kargo, dan kargo udara yang memiliki pendingin (7). Produk CCP yang perlu disimpan pada suhu tertentu perlu dilakukan pemantauan suhu. Ketika kondisi suhu dapat dipantau maka tenaga medis dapat mengetahui ketika harus membuang obat yang tidak aktif atau tidak efektif (8). Produk CCP Diantaranya, produk vaksin, suntikan, tingtur, obat oral, obat luar, produk darah dan farmasi lainnya (9). 


\section{Metode}

Metode penelitian menggunakan metode observasional, dimana bersifat deskriptif serta evaluatif dengan dilakukannya proses pemantauan dan evaluasi saat kegiatan berlangsung dan dengan metode wawancara kepada Apoteker Penanggung Jawab (APJ) PBF, kepala gudang, dan kepala ekspedisi untuk melakukan konfirmasi sistem yang diobservasi. Pengumpulan data menggunakan daftar isian (checklist) sebagai alat yang dikembangkan berdasarkan Cara Distribusi Obat yang Baik (CDOB). Penelitian dilakukan pada bulan Januari 2021 di salah satu PBF di Kota Bandung.

\section{Hasil}

CCP yang didapatkan dari PBF pusat memiliki protap tertentu baik protap penerimaan, penyimpanan, dan pengiriman ketika sampai pada PBF cabang Bandung. Pada PBF cabang Bandung, belum melakukan distribusi terhadap vaksin, tetapi untuk sarana dan prasarana distribusi vaksin sudah disediakan guna persiapan distribusi vaksin COVID19. Berikut merupakan tabel hasil observasi penanganan CCP berdasarkan pedoman CDOB yang berlaku.

Tabel 1 Hasil Observasi penanganan CCP berdasarkan CDOB

\begin{tabular}{|c|c|c|}
\hline \multirow{2}{*}{ No } & \multirow{2}{*}{$\begin{array}{c}\text { Unsur/Elemen CDOB } \\
\text { ntasi Khusus CCP }\end{array}$} & \multirow[t]{2}{*}{ Implementasi } \\
\hline & & \\
\hline 1. & Protap penerimaan, penyimpanan, dan pengiriman CCP & $\mathrm{Ya}$ \\
\hline \multirow[t]{2}{*}{2.} & Petunjuk penyimpanan CCP kepada pelanggan & $\mathrm{Ya}$ \\
\hline & Bangunan dan Penyimpanan CCP & \\
\hline 3. & Tersedia tempat terpisah untuk penyimpanan produk CCP & $\mathrm{Ya}$ \\
\hline 4. & $\begin{array}{l}\text { Tempat penyimpanan khusus untuk CCP sesuai dengan } \\
\text { kriteria (minimal chiller) }\end{array}$ & Ya \\
\hline 5. & $\begin{array}{l}\text { Dilakukan validasi terhadap tempat penyimpanan khusus } \\
\text { untuk CCP secara berkala minimal satu tahun satu kali }\end{array}$ & $\mathrm{Ya}$ \\
\hline 6. & $\begin{array}{l}\text { Suhu ruang penyimpanan CCP sesuai dengan spesifikasi } \\
\text { CCP }\end{array}$ & Ya \\
\hline 7. & $\begin{array}{l}\text { Dilengkapi dengan temperature data logger yang dapat } \\
\text { memberi informasi bahwa CCP tidak pernah mengalami } \\
\text { perubahan suhu yang merusak mutunya }\end{array}$ & $\mathrm{Ya}$ \\
\hline 8. & $\begin{array}{l}\text { Suhu ruang tempat penyimpanan dimonitor dan dicatat } \\
\text { secara berkala (minimal sehari tiga kali dengan interval } \\
\text { yang memadai) }\end{array}$ & Ya \\
\hline 10. & $\begin{array}{l}\text { Dilengkapi dengan alat yang dapat memberi peringatan } \\
\text { suhu kritis dan secara rutin dilakukan pengecekan }\end{array}$ & Ya \\
\hline 11. & $\begin{array}{l}\text { Mempunyai generator otomatis yang berfungsi dengan } \\
\text { baik, dilakukan oleh petugas yang dapat menjamin } \\
\text { generator berfungsi dengan baik selama } 24 \text { jam }\end{array}$ & $\mathrm{Ya}$ \\
\hline 12. & $\begin{array}{l}\text { Protap penanganan produk } \text { CCP apabila tempat } \\
\text { penyimpanan mengalami } \\
\begin{array}{l}\text { (contingencyplan) } \\
\text { gangguan/kerusakan }\end{array}\end{array}$ & $\mathrm{Ya}$ \\
\hline 13. & $\begin{array}{l}\text { Protap penanganan CCP jika terjadi kerusakan, } \\
\text { kadaluarsa dan tidak layak jual }\end{array}$ & Ya \\
\hline
\end{tabular}




\begin{tabular}{lll}
\hline Penyaluran CCP & \\
\hline 14. & Penyaluran CCP menggunakan wadah kedap yang \\
dilengkapi ice pack atau dengan dry ice sedemikian rupa & Ya \\
sehingga mencapai temperatur yang sesuai & \\
15. Selama transportasi vaksin ditangani sesuai dengan & $\mathrm{Ya}$ \\
\hline
\end{tabular}

Cara Distribusi dan Penyimpanan yang Baik dengan jelas menyatakan bahwa produk yang peka terhadap suhu harus disimpan, ditangani, dan didistribusikan dengan sangat hati-hati ke seluruh jaringan distribusi. Ini berfungsi sebagai persyaratan pemantauan suhu di seluruh proses rantai pasokan $(16,17)$. Implementasi pada PBF ini sudah sesuai dengan $\mathrm{CDOB}$ guna menjaga mutu dari obat yang didistribusikan. Lalu dilakukan kualifikasi pelanggan guna menjamin sarana yang menerima produk CCP adalah sarana yang legal baik secara sarna, penanggung jawab sarana, hingga pemilik dikarenakan produk CCP harus ditangani dengan khusus dan dipastikan sarana yang menerima produk CCP memenuhi kualifikasi.

\section{Pembahasan}

Pada artikel ini dilakukan penelitian pada salah satu PBF di kota Bandung yang merupakan salah satu cabang yang mendistribusikan obat-obatan dan alat kesehatan ke sesama PBF maupun hingga fasilitas kesehatan legal di seluruh kota Bandung dan sekitarnya. PBF ini telah tersertifikasi baik CDOB dan CDAKB serta mendapatkan sertifikasi ISO 9001:2008 untuk pergudangan dan distribusi farmasi, kosmetik, produk kesehatan, dan produk konsumen. Pada tahun 2010 memperoleh sertifikasi OHSAS 18001:2007 untuk sistem manajemen kesehatan dan keselamatan kerja. CCP yang disalurkan oleh PBF tersebut adalah obat-obatan hormonal, produk biologis, alat kesehatan diagnostika, dan berbagai obat-obatan serta alat kesehatan yang membutuhkan penanganan suhu $2-8^{\circ} \mathrm{C}$ pada kemasannya. Untuk pelaksanaan distribusi vaksin yang akan dilaksanakan sudah memiliki standar yang sama dengan PBF pusat yang sudah melakukan pendistribusian vaksin, dan penanganan CCP yang sudah berjalan akan sama dengan penanganan vaksin yang membutuhkan penanganan suhu $2-8^{\circ} \mathrm{C}$.

Dalam proses penanganan produk CCP, pada PBF cabang Bandung ini dilakukan oleh personel yang dipastikan memahami tanggung jawab khususnya dalam penanganan CCP dan dilakukan pelatihan terhadap personel tersebut. Dikarenakan pelatihan personel yang tidak memadai merupakan risiko yang memengaruhi kualitas rantai dingin farmasi (18). Pelatihan mencakup perundang-undangan, CDOB, prosedur tertulis, monitoring suhu dan dokumentasinya, dan respon terhadap kedaruratan dan masalah keselamatan. Pelatihan juga dilakukan terhadap pengemudi yang bertanggung jawab dalam transportasi produk rantai dingin. Untuk Produk Rantai Dingin, terdapat persyaratan khusus dimana tempat penyimpanan produk rantai dingin yaitu dalam chiller atau cold room (suhu $2^{\circ} \mathrm{C} \mathrm{s} / \mathrm{d} 8^{\circ} \mathrm{C}$ ). 
Untuk mengatasi masalah "rantai putus" dalam penyaluran CCP, para ahli menunjukkan bahwa personel harus memperbarui metode penyimpanan dan transportasi yang sesuai, dan fasilitas penyimpanan dan transportasi memerlukan kontrol suhu selama proses berlangsung (19). Kegiatan pendistribusian pada PBF dimulai dari penerimaan produk. Khusus untuk produk yang masuk aneks CDOB seperti CCP dan produk obat psikotropika terdapat beberapa perbedaan dalam penanganan.

Sebelum diterima, produk CCP dipindahkan ke area penerimaan cold storage/frozen storage untuk dilakukan bongkar dan penyimpanan (personil menggunakan APD seperti sarung tangan, masker, dll). Pengecekan yang dilakukan berupa pengecekan fisik, NIE (Nomor Izin Edar), kode pabrik, nomor bets, tanggal kadaluwarsa, kuantitas, volume dan total bobot produk (diukur menggunakan timbangan) oleh checker penerimaan. Hal ini dilakukan supaya mutu CCP tidak berubah saat proses serah terima produk dari driver pemasok ke Gudang PBF. Setelah produk dicek kemudian CCP diberi thermometer untuk kemudian dicatat suhu saat produk pertama kali masuk Gudang lalu mencatatnya pada form register suhu. Jika terjadi permasalahan pada penerimaan produk dan jika suhu tidak memasuki rentang spesifikasi/tidak ada termometer maka dibuatkan berita acara penerimaan barang yang dikirimkan kepada Apoteker Penanggung Jawab (APJ) pusat.

Pada saat peyimpanan, pengecekan suhu dilakukan sebanyak 144 kali sehari melebihi persyaratan yang ditetapkan CDOB. Hal ini bertujuan agar suhu dalam ruangan tercatat dan terkontrol oleh apoteker penanggung jawab untuk memastikan prosuk tidak mengalami perubahan kualitas. Untuk mengetahui suhu ruangan secara keseluruhan dilakukan pemetaan suhu (mapping suhu), mapping suhu merupakan kegiatan yang dilakukan untuk mengetahui keberagaman atau distribusi suhu dalam ruangan. Tujuan dari maping suhu yaitu:

1. Mengetahui fluktuasi suhu ditempat penyimpanan

2. Menentukan letak suhu kritis ditempat penyimpanan

3. Dasar untuk meletakan sensor termometer

4. Dilakukan 1 tahun sekali/sesuai perubahan layout tempat penyimpanan

5. Suhu yang tercatat kemudian didokumentasikan.

Proses maping suhu ruangan dilakukan dengan menggunakan Electronic Data Loging Monitor (EDLM) (15) merupakan instrumen yang dapat merekam kelembapan dari waktu ke waktu dan dihubungkan dengan sensornya, EDLM yang digunakan yaitu data logger (Testo $174 \mathrm{~T}$ ). Proses perekaman data di atur setiap 10 menit, dengan alert limit $3-7^{\circ} \mathrm{C}$ (untuk produk dengan spesifkasi $2-8^{\circ} \mathrm{C}$. Jika terjadi penyimpangan suhu, unit Testo akan memberikan peringatan Kepada APJ melalui email dan aplikasi pesan kepada APJ, Kepala gudang dan Area Bussiness Manager (ABM), dan kepada petugas keamanan berupa bunyi alarm buzzer dan lampu sirine. Penanggung jawab area harus selalu memastikan setiap pagi posisi alarm dalam kondisi ON dan suhu pada alarm dan testo harus sama (20). 
Alarm pada penyimpanan CCP amat sangat lah penting dikarenakan terdapat beberapa studi yang menemukan bahwa terdapat jumlah yang sangat tinggi akibat paparan yang tidak disengaja terhadap suhu beku untuk produk yang diberi label untuk penyimpanan pada $2-8^{\circ} \mathrm{C}$ karena pengiriman yang tidak tepat atau penyimpanan sementara di penyimpanan di pusat kesehatan (21).

Pada saat proses penyimpanan harus memperhatikan beberapa hal seperti: pada saat proses penyimpanan dengan penandaan yang jelas, Penyimpanan produk tidak boleh menutupi blower, produk CCP dan sitostatika disimpan di lokasi khusus yang aman. Dilakukan pencacatan suhu penyimpangan dan evaluasi suhu dilakukan sekali dalam 1 minggu oleh APJ. Data perekaman suhu yang sudah lengkap kemudian dianalisis menggunakan program Microsoft Excel. Analisis data yang dilakukan terhadap data perekaman suhu selama 1 (satu) minggu mencakup: Suhu rata-rata, suhu maksimal, suhu minimal, jumlah data yang tidak masuk dalam range, persentase data yang tidak masuk dalam range, dan durasi waktu terjadinya penyimpangan.

Lalu, untuk proses penyaluran pada bagian ekspedisi dimulai dari pencetakan faktur hingga pengiriman. Driver perlu mencetak surat jalan dan kemudian harus ditandatangani oleh kepala bagian ekspedisi. Khusus untuk produk CCP terdapat protap serta penanganan khusus. Pertama, dari segi kendaraan yang digunakan serta penyimpanan selama penghantaran/distribusi. Kendaraan yang digunakan haruslah memiliki pendingin yang termometernya terkalibrasi, untuk memastikan suhu selama penghantaran tetap terjaga. Kedua, terdapat form khusus yang harus diisi oleh driver ketika menghantarkan produk CCP. Form tersebut berisi nama produk yang diantarkan serta kuantitasnya, serta suhu penyimpanan dalam kendaraan sesaat sebelum penghantaran dan suhu penyimpanan dalam kendaraan setelah produk diterima. Ketiga, untuk produk CCP, tidak langsung dimasukkan kedalam kendaraan, namun dimasukkan kedalam cool box serta ditambahkan ice pack. Cool box tersebut baru kemudian dimasukkan kedalam kendaraan.

Cool box adalah wadah berinsulasi yang dapat dilapisi dengan kantong es untuk menjaga vaksin dan pengencer tetap dingin selama pengangkutan dan/atau penyimpanan jangka pendek (dari dua hingga tujuh hari). Cool box digunakan untuk mengumpulkan dan mengangkut pasokan vaksin bulanan dari toko distrik ke fasilitas kesehatan. Mereka juga digunakan untuk menyimpan vaksin ketika lemari es rusak atau dicairkan dan untuk penjangkauan selain pembawa vaksin (22). 
Transportasi harus dirancang sedemikian rupa untuk menjaga suhu terlepas dari suhu luar dan terhadap pengaruh lingkungan sekitar. Berbagai bahan dan teknologi yang sedang digunakan saat ini adalah untuk memastikan mutu produk dengan menggunakan dry ice, gel packs, nitrogen cair, refeer container dan lain-lain digunakan sesuai dengan standar suhu. Produk yang berbeda akan menggunakan bahan pendingin dan kemasan yang berbeda pula; biasanya gel packs untuk pendingin, dan nitrogen cair untuk pembeku, dan refeer container untuk jarak yang jauh (23). Kekurangan dalam sistem pemantauan dan pemeliharaan biasanya mempengaruhi sifat terapeutik produk dan menyebabkan kualitas risiko seperti kurangnya efek, keracunan. Dalam kasus produk rantai dingin tantangan pada perubahan suhu lebih besar, karena ada tugas untuk menjaga kondisi penyimpanan dan suhu yang memadai sepanjang siklus hidup produk (24).

Berikut adalah beberapa peralatan rantai dingin yang memiliki biaya yang mahal seperti lemari es suhu rendah, ice freezer, lemari es biasa, refeer truck, kotak berpendingin, ransel berpendingin (25). Beberapa penelitian menunjukan untuk pemilihan pemasok logistik atau PBF adalah dengan mengukur kebutuhan organisasi dengan beberapa kriteria, seperti kualitas, posisi pemasok, waktu pengiriman, dan biaya (26). Bagi produsen atau beberapa industri farmasi sangat penting untuk memastikan kualitas obat-obatan selama transportasi dan penyimpanan, yang menjadikannya sebagian besar produsen obat untuk mengevaluasi dan memilih pemasok logistik CCP dari perspektif penghindaran risiko (27).

Pemeliharaan dan pemantauan suhu botol dan vaksin di seluruh rantai pasokan merupakan prioritas penting untuk memastikan efektivitasnya. Pemeliharaan dan pemantauan suhu yang tepat juga memungkinkan pendeteksian setiap kegagalan peralatan dan penyimpangan prosedur. Untuk mengurangi risiko ekskursi suhu, pengumpulan informasi yang tepat tentang Riwayat Waktu dan Suhu (RWS) merupakan faktor kritis dan juga berharga dalam hal pengambilan keputusan. RWS berpengaruh signifikan terhadap umur simpan produk dan jika dikelola secara aktif dapat mengurangi ketidakpastian dalam pengelolaan produk (28).

Untuk melakukan pemantauan, bagian ekspedisi juga dilengkapi dengan beberapa fasilitas. Yang pertama adalah visual dashboard (VD) yang digunakan untuk memantau faktur-faktur yang telah terselesaikan maupun yang belum terselesaikan. Yang kedua adalah GPS yang terpasang pada masing-masing kendaraan. GPS tidak hanya memberikan informasi berupa posisi kendaraan, namun juga dapat memberitahukan kecepatan rata-rata kendaraan selama mendistribusikan produk, apakah mesin dalam keadaan hidup atau mati, akumulasi jarak yang telah ditempuh oleh kendaraan tersebut hingga sensor ketika pintu box dibuka. Ketelusuran memiliki peran penting dalam mengamankan obat dan dasar dalam kepercayaan konsumen pada produk yang dikirimkan (29). Dengan adanya pemantauan melalui GPS ini, sistem distribusi menjadi lebih terpantau, dan diharapkan kinerja dari masing-masing driver semakin meningkat. Setelah sampai di outlet, driver menginfokan agar produk harus langsung di simpan di kondisi sesuai spesifikasi CCP dan memberikan surat pemberitahuan penanganan CCP sesuai petunjuk penanganan CCP pada pemakai. 
Instruksi penyimpanan pada obat-obatan tidak ditulis dengan baik dan terkadang ambigu. Banyak produk farmasi tidak mencantumkan instruksi suhu, sementara beberapa produk memiliki instruksi yang berbeda. Seperti, beberapa produk memberikan instruksi penyimpanan "simpan di tempat yang sejuk", tetapi kisaran suhu tidak ditentukan (22). Maka diperlukan informasi petunjuk penyimpanan obat oleh driver yang sudah melakukan pelatihan secara berkala demi memperoleh kepuasan pelanggan (30).

\section{Kesimpulan}

Hasil evaluasi berdasarkan observasi yang telah dilakukan adalah PBF di Bandung ini sudah mengimplementasikan pendistribusian yang sesuai dengan data menggunakan daftar isian (checklist) sebagai alat yang dikembangkan berdasarkan Cara Distribusi Obat yang Baik (CDOB). Dalam proses penanganan produk CCP, pada PBF cabang Bandung ini dilakukan oleh personel yang dipastikan memahami tanggung jawab khususnya dalam penanganan CCP dan telah dilakukan pelatihan terhadap personel tersebut guna menjaga mutu dari obat yang didistribusikan.

\section{Daftar Pustaka}

1. Lloyd J, Cheyne J. The origins of the vaccine cold chain and a glimpse of the future. Vaccine [Internet]. 2017;35(17):2115-20. Available from: http://dx.doi.org/10.1016/j.vaccine.2016.11.097

2. Tsang YP, Choy KL, Wu CH, Ho GTS, Lam CHY, Koo PS. An Internet of Things (loT)-based risk monitoring system for managing cold supply chain risks. Ind Manag Data Syst. 2018;118(7):1432-62.

3. Sinha AK, Verma AR, Chandrakar A, Khes SP, Panda PS, Dixit S. Evaluation of cold chain and logistics management practice in Durg district of Chhattisgarh: pointer from Central India. Int J Community Med Public Heal. 2017;4(2):390.

4. $\mathrm{Wu} \mathrm{W}$, Zhao F, Ma C, Huang GQ. Experimental Investigation of A Real-time Monitoring System for Cold Chain Logistics. IEEE Int Conf Autom Sci Eng. 2020;2020-August:1201-6.

5. Public Health England. Storage, distribution and disposal of vaccines. Green B. 2013;17-36.

6. Kumru OS, Joshi SB, Smith DE, Middaugh CR, Prusik T, Volkin DB. Vaccine instability in the cold chain: Mechanisms, analysis and formulation strategies. Biologicals [Internet]. 2014;42(5):237-59. Available from: http://dx.doi.org/10.1016/j.biologicals.2014.05.007

7. Goldberg N, Karhi S. Online packing of arbitrary sized items into designated and multipurpose bins. Eur J Oper Res [Internet]. 2019;279(1):54-67. Available from: https://doi.org/10.1016/j.ejor.2019.05.029

8. Dwivedi AD, Srivastava G, Dhar S, Singh R. A decentralized privacy-preserving healthcare blockchain for loT. Sensors (Switzerland). 2019;19(2):1-17.

9. Li G, Wang G, Ma Y, Yue L, Zhao W. Research on Cold Chain Transport of Vaccines in Major Outbreaks. IOP Conf Ser Earth Environ Sci. 2020;526(1).

10. Sykes C. Time- and temperature-controlled transport: Supply chain challenges and solutions. P T. 2018;43(3):154-8. 
11. World health organization. How to monitor temperatures in the vaccine supply chain. World Heal Organ [Internet]. 2015;31. Available from: https://apps.who.int/iris/handle/10665/183583

12. Brison $M$, LeTallec $Y$. Transforming cold chain performance and management in lower-income countries. Vaccine [Internet]. 2017;35(17):2107-9. Available from: http://dx.doi.org/10.1016/j.vaccine.2016.11.067

13. Ashok A, Brison M, LeTallec Y. Improving cold chain systems: Challenges and solutions. Vol. 35, Vaccine. 2017.

14. Kaplinski O, Peldschus F, Nazarko J, Kaklauskas A, Baušys R. MCDM, operational research and sustainable development in the trans-border Lithuanian-GermanPolish co-operation. Eng Manag Prod Serv. 2019;11(2):7-18.

15. 윤유리. Cold Chain Management in Pharmaceutical Industry: Logistics Perspective. J Distrib Sci. 2014;12(5):33-40.

16. Bekčić S, Kelečević N, Marinković V, Tasić L, Krajnović D. Developing a quality management tool for preparing Good Distribution Practice audit of pharmaceutical contract vaccine distributor. Indian J Pharm Educ Res. 2015;49(3):174-82.

17. Kartoglu U, Vesper J, Teräs H, Reeves T. Experiential and authentic learning approaches in vaccine management. Vaccine [Internet]. 2017;35(17):2243-51. Available from: http://dx.doi.org/10.1016/j.vaccine.2016.11.104

18. Hibbs BF, Miller E, Shi J, Smith K, Lewis P, Shimabukuro TT. Safety of vaccines that have been kept outside of recommended temperatures: Reports to the Vaccine Adverse Event Reporting System (VAERS), 2008-2012. Vaccine [Internet]. 2018;36(4):553-8. Available from: https://doi.org/10.1016/j.vaccine.2017.11.083

19. Maglasang PLF, Butalid MLC, Pastoril MF, Pratama ANW, Tan EY. A cross-sectional survey on cold chain management of vaccines in Cebu, Philippines. Pharm Pract (Granada). 2018;16(2):1-6.

20. Maule E, Eastman W, March E. Temperature Management of Medicines Storage and Transport. 2016;(September):12-78.

21. McColloster PJ. US vaccine refrigeration guidelines: Loose links in the cold chain. Hum Vaccin. 2011;7(5):574-5.

22. Shafaat K. An Overview: Storage of Pharmaceutical Products. World J Pharm Pharm Sci. 2013;2(October):2499-515.

23. Rodrigue J-P, Comtois C, Slack B. Transport, energy and environment. Geogr Transp Syst. 2019;288-310.

24. Kumar N, Jha A. Temperature excursion management: A novel approach of quality system in pharmaceutical industry. Saudi Pharm J [Internet]. 2017;25(2):176-83. Available from: http://dx.doi.org/10.1016/j.jsps.2016.07.001

25. Yongjing $X$, Liying $Y$. Optimization of Pharmaceutical Cold Chain Logistics Distribution Based on New GSP Standard. J J Shanghai Univ. 2017;5.

26. Forghani A, Sadjadi SJ, Moghadam BF. A supplier selection model in pharmaceutical supply chain using PCA, Z-TOPSIS and MILP: A case study. PLoS One. 2018;13(8):1-17.

27. Wen Z, Liao H, Ren R, Bai C, Zavadskas EK, Antucheviciene J, et al. Cold chain logistics management of medicine with an integrated multi-criteria decision-making method. Int J Environ Res Public Health. 2019;16(23):1-21.

28. Ketzenberg M, Bloemhof J, Gaukler G. Managing perishables with time and temperature history. Prod Oper Manag. 2015;24(1):54-70. 
29. Chiacchio F, D'Urso D, Compagno L, Chiarenza M, Velardita L. Towards a Blockchain Based Traceability Process: A Case Study from Pharma Industry. In: IFIP Advances in Information and Communication Technology. United States: IFIP International Conference on Advances in Production Management Systems (APMS); 2019. p. 451-7.

30. Gligor D, Gligor N, Holcomb M, Bozkurt S. Distinguishing between the concepts of supply chain agility and resilience: A multidisciplinary literature review. Int $\mathrm{J}$ Logist Manag. 2019;30(2):467-87. 